\title{
High flow nasal cannula oxygen vs. bag-valve- mask for preoxygenation before intubation in patients with hypoxemic respiratory failure - a prospective randomized trial
}

M Simon", D Frings, C Wachs, S Braune, S Kluge

From ESICM LIVES 2015

Berlin, Germany. 3-7 October 2015

\section{Introduction}

Scheduled endotracheal intubation for elective surgery is generally considered a safe procedure. In contrast, critically ill patients in the intensive care unit (ICU), especially those with respiratory failure, have an increased risk for hypoxemia-related complications. An increasingly used means of oxygen delivery is its application via high flow nasal cannula (HFNC).

\section{Objectives}

This study was conducted to compare HFNC with bagvalve-mask (BVM) for preoxygenation prior to intubation in patients with hypoxemic respiratory failure.

\section{Methods}

Prospective randomized trial randomizing 40 critically ill patients with hypoxemic respiratory failure to receive either HFNC or BVM for preoxygenation before intubation in the ICU.

\section{Results}

Mean $\mathrm{PaO}_{2} / \mathrm{FiO}_{2}$ at baseline was $200 \pm 57 \mathrm{~mm} \mathrm{Hg}$ in the HFNC group and $205 \pm 59 \mathrm{~mm} \mathrm{Hg}$ in the BVM group $(\mathrm{p}=0.76)$. Mean $\mathrm{SpO}_{2}$ at baseline was $96 \pm 3 \%$ in the HFNC group and $94 \pm 4 \%$ in the BVM group $(\mathrm{p}=0.24)$. The mean lowest oxygen saturation measured by pulse oximetry $\left(\mathrm{SpO}_{2}\right)$ during intubation was $89 \pm 18 \%$ in the HFNC group and $86 \pm 11 \%$ in the BVM group $(\mathrm{p}=$ 0.56). During the one minute of apnea after the induction of anesthesia, $\mathrm{SpO}_{2}$ dropped significantly in the BVM group ( $\mathrm{p}=0.001)$, while there was no significant difference in the HFNC group $(\mathrm{p}=0.17)$. There were no significant differences between the two groups at any of the predefined time points concerning $\mathrm{SpO}_{2}, \mathrm{PaO}_{2} / \mathrm{FiO}_{2}, \mathrm{PaCO}_{2}$, heart rate and mean arterial pressure.

\section{Conclusions}

Preoxygenation using HFNC prior to intubation was safe in critically ill patients with hypoxemic respiratory failure. There were no significant differences in gas exchange before and after intubation comparing the HFNC group and the BVM group. However, in contrast to the BVM group there was no significant decrease in $\mathrm{SpO}_{2}$ during the apnea phase prior to intubation within the HFNC group.

Published: 1 October 2015

\section{doi:10.1186/2197-425X-3-S1-A934}

Cite this article as: Simon et al: High flow nasal cannula oxygen vs. bag-valve-mask for preoxygenation before intubation in patients with hypoxemic respiratory failure - a prospective randomized trial. Intensive Care Medicine Experimental 2015 3(Suppl 1):A934. 